\title{
Genes with homology to mammalian apoptosis regulators identified in zebrafish
}

\begin{abstract}
Dear Editor,
Programmed cell death (PCD) is an evolutionarily conserved mechanism of cellular demise developed by metazoans to delete cells during development and to maintain homeostasis in adult tissues. ${ }^{1}$ Genetic analyses of the cell death process in model organisms, most notably in the nematode Caenorhabditis elegans, have provided critical insight into the genetic pathway for programmed cell death. ${ }^{2,3}$ Such analyses have revealed a high level of functional and molecular conservation in the components and regulation of the cell death pathway between invertebrates and mammals. ${ }^{2,3}$ Zebrafish (Danio rerio) is an excellent genetic model for the study of vertebrate development and disease. ${ }^{4}$ The zebrafish model is expected to bridge the gap between the Caenorhabditis elegans/Drosophila and mouse/human models.
\end{abstract}

There have been few reports regarding the apoptotic process in zebrafish. It has been shown that cells from zebrafish embryos develop morphological features of apoptosis including DNA fragmentation after treatment of whole embryos with a variety of agents including nocodazole, aphidicolin and camptothecin. ${ }^{5,6}$ However, with the exception of p53, ${ }^{7}$ no apoptosis regulatory genes have been described in zebrafish. To identify zebrafish genes encoding products with homology to mammalian apoptosis proteins, we searched expressed-sequence tags (EST) public databases for zebrafish homologs proteins using TBLAST. ${ }^{8}$ The analysis identified 37 zebrafish genes with significant homology to mammalian apoptosis genes in EST databases (Table 1). A more detailed description of current and updated results can be viewed in a Web page at http://www-personal.umich.edu/ ino/List/zebrafishEST.html. The analysis revealed a remarkable conservation of apoptosis pathways between zebrafish and mammals (Table 1). Both death receptor and mitochondrial-Apaf-1 pathways appeared conserved, in that essential components of these pathways were present in zebrafish. Several proteins with significant homology to bird and mammalian death receptors including TRAILR1 (CAR1), NGFR1, DR3, and DR6 were identified in zebrafish. In addition, one zebrafish protein with homology to TRAIL, a ligand for TRAILR1 was present in EST databases. Thus, zebrafish appears to be a suitable model organism to study death receptor pathways.

We identified several zebrafish proteins with significant homology to mammalian caspases including Caspase-2, $-3,-6,-8,-9$ and -13 . Zebrafish caspases with long prodomains included Caspase-8 that contained death effector domains (DED) and Caspase-2 and Caspase-9 that contained recognizable caspase-recruitment domains (CARDs), as they are found in their mammalian counter- parts (Table 1). Another zebrafish caspase with a long prodomain was most homologous to Caspase-13, which in humans contains a CARD. Of interest is that the prodomain of the zebrafish Caspase-13 homolog lacked a CARD, but it contained sequence homology to a region present in the $\mathrm{N}$-terminus of pyrin, the protein mutated in patients with familial Mediterranean fever. ${ }^{9}$ In addition, the pyrin-related region of zebrafish Caspase- 13 was highly homologous to a region found in the zebrafish homolog of ASC1 $\left(e=2 \times 10^{-31}\right)$. Several homologs of mammalian caspase regulators such as Apaf-1, IAP1 and XIAP were also identified in zebrafish (Table 1). Zebrafish Apaf-1 contained CARD, nucleotide-binding oligomerization domain (NOD) and WD-40 repeats, suggesting that like mammalian Apaf-1, ${ }^{10}$ zebrafish Apaf- 1 might regulate Caspase-9 in a cytochrome c-dependent manner. In addition, we identified a homolog of Nod1, an Apaf-1-like molecule that regulates apoptosis and NF- $\kappa \mathrm{B}$ activation. ${ }^{11,12}$ Several proteins with significant homology to $\mathrm{Bcl}-2$ family members were identified in zebrafish. They included proteins with homology to Mcl-1 (two different genes), Bcl-XL, quail NR-13, Bax, Bad, Nip3 and Nip3L. As expected, these proteins contained conserved $\mathrm{BH} 1-4$ domains with the exception of $\mathrm{Bcl}-\mathrm{X}_{\mathrm{L}}$ (most homologous to chick $B c l-X_{L}$ ) in which the sequences available in two EST cDNAs were truncated and only the $\mathrm{BH} 2$ motif was identified (Table 1). The putative Bad homolog in zebrafish contained the serine residue corresponding to Ser136 in mammalian Bad that is phosphorylated by the Akt kinase. Notably, zebrafish Nip3 and NIP3L lacked recognizable $\mathrm{BH} 3$ motifs. Several proteins with significant homology to mammalian regulators of DNA fragmentation and condensation were also identified in zebrafish. They included AIF, CIDE-A, and Acinus. These results suggest conservation of the final steps of apoptosis in zebrafish and mammals.

The present analysis was based on over 50000 zebrafish EST sequences that have been deposited in GenBank. Ultimately, the zebrafish genome project currently underway will make available a much larger number of ESTs, allowing the identification of most, if not all, apoptosis regulatory genes in zebrafish. The results provided herein should foster genetic work in zebrafish that might lead to the elucidation of programmed cell death pathways in this organism. Genetic screens in zebrafish have led to the identification of a large number of mutations in genes that play important roles in devlopmental events. ${ }^{4}$ Several of these mutations are known to affect neural survival and some of them exhibit increased apoptosis in regions of the brain, spinal cord or 
Table 1 Apoptosis regulators found in Zebrafish EST database

\begin{tabular}{|c|c|c|c|c|c|}
\hline $\begin{array}{l}\text { Protein } \\
\text { family }\end{array}$ & $\begin{array}{l}\text { Protein } \\
\text { name }\end{array}$ & E-value & Most homologous gene & Domain found & GenBank account number of EST \\
\hline \multirow[t]{8}{*}{$\mathrm{Bcl}-2$} & Mcl-1a & $3 \times 10^{-39}$ & Human Mcl-1 & $\mathrm{BH} 1-4 . \mathrm{HT}$ & Al558399, Al332103, Al54458, others \\
\hline & $\mathrm{Mcl}-1 \mathrm{~b}$ & $5 \times 10^{-17}$ & Mouse Mcl-1 & $\mathrm{BH} 1-4$ & AW184718, AW184356, AW184356 \\
\hline & Bcl-xL & $4 \times 10^{-23}$ & Chick Bcl-x & $\mathrm{BH} 2, \mathrm{HT}$ & AI331490, AI332098 \\
\hline & NR-13 & $1 \times 10^{-29}$ & Quail NR-13 & $\mathrm{BH} 1-4, \mathrm{HT}$ & AW076878, Al616662 \\
\hline & Bax & $2 \times 10^{-46}$ & Bovine Bax & $\mathrm{BH} 1-4, \mathrm{HT}$ & AW127841, Al877666, AW184600, others \\
\hline & Bad & $7 \times 10^{-16}$ & Rat Bad & $\mathrm{PSD}, \mathrm{BH} 3$ & Al332008, Al330583 \\
\hline & Nip3 & $2 \times 10^{-21}$ & Mouse Nip3 & $\mathrm{HT}$ & Al877860, A1793810 \\
\hline & Nip3L & $2 \times 10^{-58}$ & Human Bnip3L & HT & Al476912, Al601667, Al476912 \\
\hline \multirow[t]{6}{*}{ Caspase } & Caspase-2 & $2 \times 10^{-59}$ & Chick Caspase-2 & CARD, LS, SS & AW174100, Al815362, Al815376, others \\
\hline & Caspase-3 & $8 \times 10^{-44}$ & Chinese hamster Caspase-3 & LS, SS & Al958296 \\
\hline & Caspase-6 & $1 \times 10^{-72}$ & Mouse Caspase- 6 & LS, SS & Al958815 \\
\hline & Caspase-8 & $5 \times 10^{-28}$ & Mouse Caspase-8 & DED, SS & Al722045, Al815362, Al815376, others \\
\hline & Caspase-9 & $5 \times 10^{-15}$ & Human Caspase-9 & CARD, LS & Al722734 \\
\hline & Caspase-13 & $1 \times 10^{-4}$ & Human Caspase-13 & PYRN, LS, SS & Al331460, Al332068 \\
\hline \multirow[t]{2}{*}{ Ced-4-like } & Apaf-1 & $1 \times 10^{-35}$ & Human Apaf-1 & CARD, NOD, WDR & Al722160, Al722572 \\
\hline & Nod1 & $2 \times 10^{-11}$ & Human Nod1 & NOD & Al883819 \\
\hline \multirow[t]{2}{*}{ IAP } & IAP1 & $2 \times 10^{-73}$ & Human IAP1 & BIR, CARD, RING & Al667590, Al496684, Al497515, others \\
\hline & XIAP & $1 \times 10^{-43}$ & Mouse XIAP & BIR & Al558531 \\
\hline DED & DEDD & $2 \times 10^{-25}$ & Mouse DEDD & DED & Al629267, AW174683, AW165131, others \\
\hline CARD & ASC1 & $3 \times 10^{-15}$ & Human ASC & PYRN, CARD & AW174631, Al384922, AW233497 \\
\hline CIDE/DFF & CIDE-A & $6 \times 10^{-18}$ & Mouse CIDE-A & CIDE-N, CIDE-C & Al979389, Al974197 \\
\hline DD mediator & TRADD & $5 \times 10^{-37}$ & Human TRADD & DD & Al943007, Al959035, Al616949, others \\
\hline \multirow[t]{3}{*}{ Death receptor } & TRAILR1 & $2 \times 10^{-16}$ & Turkey ALV receptor & CLD & Al722914, Al722436 \\
\hline & NGFR1 & $7 \times 10^{-37}$ & Chick NGFR & CLD, TM, DD & Al437140, Al629342 \\
\hline & DR6 & $2 \times 10^{-15}$ & Human DR6 & CLD & AW153974, Al331870 \\
\hline Death ligand & TRAIL & $6 \times 10^{-16}$ & Human TRAIL & MLR & Al626285, Al601847 \\
\hline \multirow{11}{*}{ Other } & Acinus & $1 \times 10^{-85}$ & Human Acinus & & AW059158, Al545316, AW174821, others \\
\hline & AIF & $5 \times 10^{-49}$ & Mouse AIF & & Al477772, AW128741, Al353961, others \\
\hline & Ask1a & $3 \times 10^{-51}$ & Human Ask1 & & Al497484 \\
\hline & Ask1b & $9 \times 10^{-31}$ & Mouse Ask1 & & Al330777, Al330529 \\
\hline & DAP kinase & $1 \times 10^{-83}$ & Human DAPK & ANKR & AW184120, AW203120 \\
\hline & DAP-a & $3 \times 10^{-24}$ & Human DAP & & Al626584, Al626458, AW019267 \\
\hline & DAP-b & $8 \times 10^{-09}$ & Human DAP & & Al397217, Al353222, Al616885 \\
\hline & $\mathrm{DAXX}$ & $2 \times 10^{-13}$ & Human DAX & & Al883093, Al6677252 \\
\hline & FLASH & $8 \times 10^{-43}$ & Mouse FLASH & & Al942728, Al884180 \\
\hline & p84 & $1 \times 10^{-85}$ & Human p84 & DD & AW173977, AW171143, Al882808, others \\
\hline & $\mathrm{Bl}-1$ & $2 \times 10^{-54}$ & Human TEGT & & Al964949 \\
\hline
\end{tabular}

Abbreviations: ANKR, ankyrin repeat; BH1-4, Bcl-2 homology domain 1 to 4; BIR, baculovirus IAP-homology region; CARD, caspase-recruitment domain; CIDE-N and CIDE-C, N-terminal and C-terminal conserved domains of CIDEs, respectively; CLD, Cysteine-rich ligand-binding domain; DD, death domain; DED, death effector domain; HT, hydrophobic tail; LS, caspase large subunit; MLR, mature ligand domain; NOD, nucleotide-binding oligomeriziation domain; PSD, phosphoserine-containing domain; PYRN, pyrin N-terminal homology domain; RING, RING-finger; SS, caspase small subunit; TM, transmembrane domain; WDR, WD40 repeats-containing domain; E-values were calculated according to BLASTP except for zebrafish Bcl-xL that was calculated by PSI-BLAST

retina. $^{13-15}$ The identification of the genes involved and further genetic studies in zebrafish might provide important insight into human diseases with similar phenotypes.

\section{N Inohara ${ }^{* 1}$ and G Nuñez ${ }^{1}$}

${ }^{1}$ Department of Pathology and Comprehensive Cancer Center, University of Michigan Medical School, Ann Arbor, MI 48109, USA

*Corresponding author: N Inohara, Department of Pathology and Comprehensive Cancer Center, University of Michigan Medical School, Ann Arbor, MI 48109, USA. Tel: 734-764-8514; Fax: 734-647-9654;

E-mail: ino@umich.edu

1. Jacobson MD et al. (1997) Cell 88: 347-354

2. Metzstein MM et al. (1998) Trends. Genet. 14: 410-416

3. Abrams JM (1999) Trends. Cell Biol. 9: 435-440

4 Fishman MC (1999) Proc. Natl. Acad. Sci. USA 96: 10554-10556
5. Ikegami R et al. (1997) Zygote 5: 329-350

6. Ikegami R et al. (1999) Dev. Biol. 209: 409-433

7. Chen R et al. (1997) Mol. Mar. Biol. Biotechnol. 6: 88-97

8. Altschul SF et al. (1990) J. Mol. Biol. 215: 403-410

9. The International FMF Consortium (1997) Cell 90: 797-807

10. Li P et al. (1997) Cell 91: 479-489

11. Bertin J et al. (1999) J. Biol. Chem. 274: 12955-12958

12. Inohara N et al. (1999) J. Biol. Chem. 274: 14560-14567

13. Abdelilah S et al. (1996) Development 123: 217-227

14. Furutani-Seiki M et al. (1996) Development 123: 229-230

15. Rodriguez M and Driever W (1997) Biochem. Cell Biol. 75: 570-600 